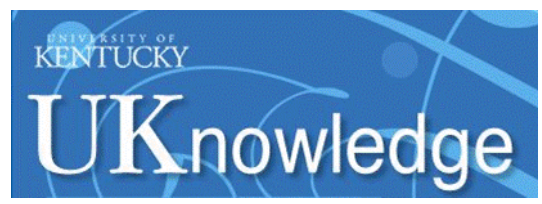

University of Kentucky

UKnowledge

7-12-2018

\title{
Cross Photoreaction of Glyoxylic and Pyruvic Acids in Model Aqueous Aerosol
}

\author{
Sha-Sha Xia \\ University of Kentucky, shasha.xia@uky.edu
}

Alexis J. Eugene

University of Kentucky, alexis.eugene@uky.edu

Marcelo I. Guzman

University of Kentucky, marcelo.guzman@uky.edu

Follow this and additional works at: https://uknowledge.uky.edu/chemistry_facpub

Part of the Analytical Chemistry Commons, Biochemistry Commons, Environmental Chemistry

Commons, Environmental Engineering Commons, Environmental Health Commons, Environmental

Sciences Commons, and the Physical Chemistry Commons

Right click to open a feedback form in a new tab to let us know how this document benefits you.

\section{Repository Citation}

Xia, Sha-Sha; Eugene, Alexis J.; and Guzman, Marcelo I., "Cross Photoreaction of Glyoxylic and Pyruvic Acids in Model Aqueous Aerosol" (2018). Chemistry Faculty Publications. 151.

https://uknowledge.uky.edu/chemistry_facpub/151

This Article is brought to you for free and open access by the Chemistry at UKnowledge. It has been accepted for inclusion in Chemistry Faculty Publications by an authorized administrator of UKnowledge. For more information, please contact UKnowledge@lsv.uky.edu. 


\section{Cross Photoreaction of Glyoxylic and Pyruvic Acids in Model Aqueous Aerosol}

Digital Object Identifier (DOI)

https://doi.org/10.1021/acs.jpca.8b05724

\section{Notes/Citation Information}

Published in The Journal of Physical Chemistry A, v. 122, issue 31, p. 6457-6466.

Copyright @ 2018 American Chemical Society

This is an open access article published under an ACS AuthorChoice License, which permits copying and redistribution of the article or any adaptations for non-commercial purposes. 


\title{
Cross Photoreaction of Glyoxylic and Pyruvic Acids in Model Aqueous Aerosol
}

\author{
Sha-Sha Xia, Alexis J. Eugene, and Marcelo I. Guzman*(0) \\ Department of Chemistry, University of Kentucky, Lexington, Kentucky 40506, United States \\ Supporting Information
}

\begin{abstract}
Aerosols of variable composition, size, and shape are associated with public health concerns as well as with light-particle interactions that play a role in the energy balance of the atmosphere. Photochemical reactions of 2oxocarboxylic acids in the aqueous phase are now known to contribute to the total secondary organic aerosol (SOA) budget. This work explores the cross reaction of glyoxylic acid (GA) and pyruvic acid (PA) in water, the two most abundant 2-oxocarboxylic acids in the atmosphere, under solar irradiation and dark thermal aging steps. During irradiation, PA and GA are excited and initiate proton-coupled electron

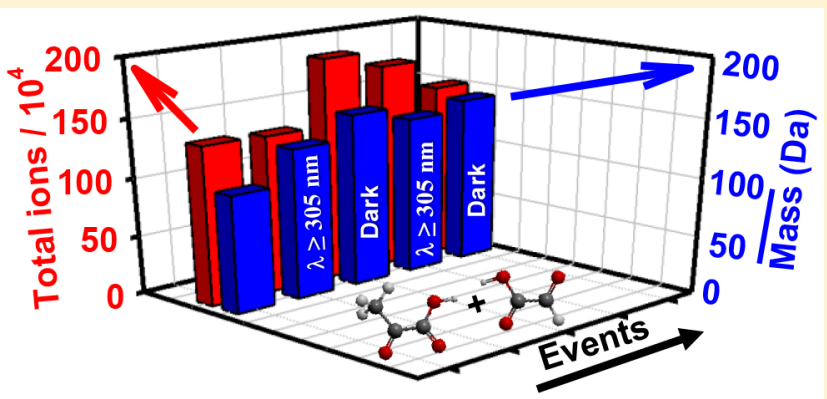
transfer or hydrogen abstraction and $\alpha$-cleavage reactions, respectively. The time series of photoproducts is studied by ion chromatography (IC) with conductivity and electrospray ionization (ESI) mass spectrometry (MS) detection, direct ESI-MS analysis in the negative ion mode, and nuclear magnetic resonance spectroscopy (NMR). The use of one-dimensional $\left({ }^{1} \mathrm{H}\right.$ and ${ }^{13} \mathrm{C}$ NMR) and two-dimensional NMR techniques includes gradient correlation spectroscopy (gCOSY) and heteronuclear single quantum correlation (HSQC). The aging of photoproducts in the dark is monitored by UV-visible spectroscopy. The periodicity in the time domain of the optical properties is explained in terms of chromophores that undergo alternating thermochromism and photobleaching between nighttime and daytime cycles, respectively. A reaction mechanism for the cross reaction of GA and PA explaining the generation of trimers with general formulas $\mathrm{C}_{5} \mathrm{H}_{8} \mathrm{O}_{5}(148 \mathrm{Da}), \mathrm{C}_{6} \mathrm{H}_{10} \mathrm{O}_{5}(162 \mathrm{Da})$, and $\mathrm{C}_{5} \mathrm{H}_{8} \mathrm{O}_{6}(164 \mathrm{Da})$ is provided based on all experimental observations.
\end{abstract}

\section{INTRODUCTION}

Photochemical reactions in the aqueous phase can contribute significantly to the total secondary organic aerosol (SOA) budget. ${ }^{1,2}$ Simple 2-oxocarboxylic acids such as glyoxylic acid (GA) and pyruvic acid (PA) can photogenerate radicals in the aqueous phase, ${ }^{3-7}$ where inorganic electrolytes such as ammonium and sulfate can participate in thermal processes. ${ }^{7-9}$ $\mathrm{GA}\left(\mathrm{p} K_{a}=3.13\right)^{10}$ and PA $\left(\mathrm{p} K_{a}=2.39\right)^{11}$ are widely available in aqueous SOA due to the photo-oxidative processing of isoprene $\mathrm{e}^{12-14}$ and aromatics ${ }^{15-19}$ forming them. ${ }^{17-19} \mathrm{GA}$ and PA are the two most abundant 2-oxocarboxylic acids in organic aerosols identified at different sites. ${ }^{20-22}$ The net rates of GA and PA generation in atmospheric waters are $2.95( \pm 0.89) \times$ $10^{10}$ mol year $^{-1} \equiv 0.71( \pm 0.21) \mathrm{TgC}_{\text {year }}{ }^{-1}$ and $1.80( \pm 0.46)$ $\times 10^{9}$ mol year $^{-1} \equiv 64.7( \pm 16.7) \mathrm{GgC}$ year $^{-1}$, respectively. $^{23}$ The partitioning of GA and PA into the particle phase can be as high $88 \%$ and $67 \%$, respectively. ${ }^{24}$

Our previous work has explained the chemical fate of GA and PA during self-photoreactions. ${ }^{6,7,9}$ However, the cross photoinduced reaction of GA and PA and the possible associated mechanism for this process has remained unexplored and is tackled here for the first time. This laboratory work reports how sunlight can trigger the cross photoreaction of GA and PA in atmospheric water mimics. Then, thermal reactions of the photoproducts are monitored during dark periods. Photoproducts are identified and monitored during the reaction by (1) ion chromatography (IC) with dual conductivity and electrospray (ESI) mass spectrometric (MS) detection, (2) direct ESI-MS analysis in the negative ion mode, and (3) nuclear magnetic resonance spectroscopy (NMR) analysis including one-dimensional $\left({ }^{1} \mathrm{H}\right.$ and ${ }^{13} \mathrm{C}$ NMR), and two-dimensional gradient correlation spectroscopy (gCOSY) and heteronuclear single quantum correlation (HSQC) experiments.

\section{MATERIALS AND EXPERIMENTAL METHODS}

Preparation of Experiments and Controls. Mixtures of PA (Sigma-Aldrich, 99.1\%) and GA (Sigma-Aldrich, $51.7 \mathrm{wt} \%$ in $\mathrm{H}_{2} \mathrm{O}$ ) were prepared daily in ultrapure water (Elga Purelab flex, 18.2 M $\Omega \mathrm{cm}^{-1}$ ). The mixture of $30-50 \mathrm{mM} \mathrm{PA}$ and 250 $-300 \mathrm{mM}$ GA was doped with inorganic electrolytes including $\left[\mathrm{Na}^{+}\right]=468 \mathrm{mM},\left[\mathrm{Cl}^{-}\right]=545 \mathrm{mM}$ and $\left[\mathrm{SO}_{4}{ }^{2-}\right]=28.2 \mathrm{mM}$ prepared from $\mathrm{NaCl}$ (Fisher, 100.3\%), $\mathrm{Na}_{2} \mathrm{SO}_{4}$ (Fisher, $100.1 \%$ ) and $\mathrm{HCl}$ (EMD, 37.7\%). Additional environmental considerations explaining all the previous concentrations are provided in the Supporting Information. The mixture was

Received: June 15, 2018

Revised: July 11, 2018

Published: July 12, 2018 
adjusted to $\mathrm{pH} 1.0$ with $[\mathrm{HCl}]=2.0 \mathrm{M}$, and $180.0 \mathrm{~mL}$ were transferred to a customized fused silica photoreactor of 220.0 $\mathrm{mL}$ capacity. The reactor was sealed and ethanol (Ricca, $69.6 \%$ $\mathrm{v} / \mathrm{v}$ ) was recirculated through a jacket (Thermo Scientific, A25 bath circulator) to keep the temperature at $298 \mathrm{~K}$. Solutions underwent continuous sparging at a flow rate of $100 \mathrm{~mL} \mathrm{~min}{ }^{-1}$ with 1 atm air (Scott-Gross, UHP) starting $30 \mathrm{~min}$ before photolysis for $\left[\mathrm{O}_{2}(\mathrm{aq})\right]_{0}=0.26 \mathrm{mM}$. The control experiments in Table 1 were designed to study the effect of inorganic

Table 1. Experiments and Controls To Investigate the Cross Reaction of GA and $\mathbf{P A}^{a}$

\begin{tabular}{lcccccc} 
& \multicolumn{5}{c}{ conditions } \\
\cline { 2 - 6 } & & & \multicolumn{4}{c}{ atmosphere } \\
\cline { 2 - 6 } & $h \nu$ & electrolytes & air & $\mathrm{N}_{2}$ & $\mathrm{O}_{2}$ \\
experiment & $\mathrm{X}$ & $\mathrm{X}$ & $\mathrm{X}$ & & \\
control A & $\mathrm{X}$ & $\mathrm{X}$ & & $\mathrm{X}$ & \\
control B & $\mathrm{X}$ & $\mathrm{X}$ & & & $\mathrm{X}$ \\
control C & $\mathrm{X}$ & & $\mathrm{X}$ & & \\
control D & $\mathrm{X}$ & & & $\mathrm{X}$ & \\
control E & $\mathrm{X}$ & & & & $\mathrm{X}$ \\
control F & & $\mathrm{X}$ & $\mathrm{X}$ & &
\end{tabular}

${ }^{a} h \nu$ indicates the presence of light. Electrolytes include $\mathrm{Na}^{+}, \mathrm{Cl}^{-}$, and $\mathrm{SO}_{4}{ }^{2-}$.

electrolytes and the concentration of $\mathrm{O}_{2}(\mathrm{~g})$ on the cross reaction of GA and $\mathrm{PA}$, and included: Control A under $1 \mathrm{~atm}$ $\mathrm{N}_{2}(\mathrm{~g})$ (Scott-Gross, UHP), control B under 1 atm $\mathrm{O}_{2}(\mathrm{~g})$ (Scott-Gross, UHP) for $\left[\mathrm{O}_{2}(\mathrm{aq})\right]_{0}=1.24 \mathrm{mM}$, control $\mathrm{C}$ without electrolytes, control D without electrolytes under 1 atm $\mathrm{N}_{2}(\mathrm{~g})$, control $\mathrm{E}$ without electrolytes under 1 atm $\mathrm{O}_{2}(\mathrm{~g})$, and control $\mathrm{F}$ without light.

Photochemical Experiments and Thermal Treatment of Photolyzed Samples. The photochemical setup employed includes a $1 \mathrm{~kW}$ high-pressure $\mathrm{Xe}-\mathrm{Hg}$ lamp (Newport). A water filter was used (Newport) to remove unwanted infrared radiation, and a cutoff filter (Oriel) at $\lambda \geq 305 \mathrm{~nm}$ provided actinic radiation in the solar window. Potassium ferrioxalate (Alfa Aesar, 98.9\%) was used as an actinometer to measure the actinic flux $\left(1.06 \times 10^{-5}\right.$ Einstein $\mathrm{L}^{-1} \mathrm{~s}^{-1}$ for $\lambda \geq$ $305) .{ }^{25}$ During the first stage of processing (Stage I in Scheme 1 ), samples of the experiment and controls (Table 1) were irradiated for $6 \mathrm{~h}$ and $5.0 \mathrm{~mL}$ aliquots were withdrawn from the reactor at $0,0.5,1,2,3,4,5$, and $6 \mathrm{~h}$. A $30 \%$ of the aliquot was immediately frozen at $-20{ }^{\circ} \mathrm{C}$ and stored in the dark for later analyses by IC-ESI-MS, direct ESI-MS, and NMR spectroscopy. The analysis of freshly photolyzed samples (before freezing) by these techniques verified that none of the products reported could result from the freezing process. The remaining $3.5 \mathrm{~mL}$ of sample was transferred to a Suprasil cuvette (Starna Cells, $10 \mathrm{~mm}$ optical path length) to monitor its aging (Stage II in Scheme 1) in the dark by UV-visible spectroscopy for $15 \mathrm{~h}$ at $298 \mathrm{~K}$ followed by $9 \mathrm{~h}$ at $323 \mathrm{~K}$. The same analyses performed on the irradiated samples were also applied to the aged samples after dark periods.

About $130.0 \mathrm{~mL}$ of the remaining photolyzed sample was stored in the dark for $24 \mathrm{~h}$ and then rephotolyzed (Stage III in Scheme 1) under the same conditions previously described. The later rephotolyzed samples underwent a second aging process in the dark monitored by UV-visible spectroscopy (Stage IV in Scheme 1). The conversions of individual samples
Scheme 1. Representation of the Processing of Glyoxylic Acid (GA) and Pyruvic Acid (PA) Mixtures ${ }^{a}$
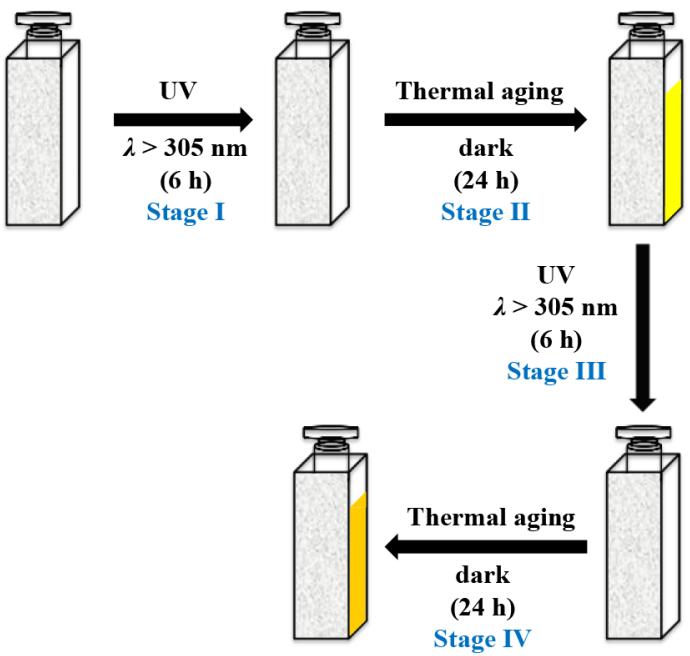

${ }^{a}$ Stages I and III are both $6 \mathrm{~h}$ photolysis periods. Stages II and IV each refer to (dark) thermal aging during $15 \mathrm{~h}$ at $298 \mathrm{~K}$ followed by $9 \mathrm{~h}$ processing at $323 \mathrm{~K}$. Adapted from ref 7.

of GA and PA have been previously reported in the same setup. $6,7,26,27$

Analysis of Products. Samples were analyzed by (1) UVvisible spectroscopy, (2) IC-MS also equipped with a conductivity detector, (3) direct infusion electrospray mass spectroscopy (ESI-MS) in the negative ionization mode, and (4) a combination of nuclear magnetic resonance spectroscopy (NMR) experiments including one-dimensional (1D) ${ }^{1} \mathrm{H}$ and ${ }^{13} \mathrm{C} \mathrm{NMR}$, and two-dimensional (2D) gradient correlation spectroscopy (gCOSY), and heteronuclear single quantum correlation (HSQC). The uncertainty associated with UVvisible spectroscopy, IC-MS, and ESI-MS measurements, based on the propagation of systematic errors, ${ }^{28}$ was lower than $1.0 \%$. The presence or absence of carbonyl groups in the cross products was verified by UHPLC-MS analysis of samples derivatized with 2,4-dinitrophenylhydrazine (DNPH).

UV-visible spectra $(190 \leq \lambda \leq 750 \mathrm{~nm})$ of initial and irradiated samples were recorded immediately after sampling with an Evolution 220 scanning spectrophotometer (Thermo Scientific) equipped with a temperature controlled multicell holder (Thermo Scientific, SPE $8 \mathrm{~W}$ ). In addition, spectra were recorded during the aging processing every $30 \mathrm{~min}$. Actual initial concentrations of GA and PA in the mixture were solved from total absorbance using Beer's law and the calculated molar absorption coefficients of pure GA $\left(\varepsilon_{\mathrm{GA}}=11.6 \mathrm{M}^{-1}\right.$ $\mathrm{cm}^{-1}$ at $\left.\lambda=240 \mathrm{~nm}\right)^{29}$ and PA $\left(\varepsilon_{\mathrm{PA}}=11.3 \mathrm{M}^{-1} \mathrm{~cm}^{-1}\right.$ at $\lambda=$ $320 \mathrm{~nm})^{15}$ standard solutions in water. Multiple wavelengths $(\lambda=260,270,280,290,300$, and $320 \mathrm{~nm})$ were chosen to calculate the molar absorption coefficient of each standard and their relative contribution to the total absorbance in the mixture. The molar absorption coefficients were calculated for $\mathrm{PA}\left(\varepsilon_{260}=26.7 \mathrm{M}^{-1} \mathrm{~cm}^{-1}, \varepsilon_{270}=7.50 \mathrm{M}^{-1} \mathrm{~cm}^{-1}, \varepsilon_{280}=5.00\right.$ $\mathrm{M}^{-1} \mathrm{~cm}^{-1}, \varepsilon_{290}=5.70 \mathrm{M}^{-1} \mathrm{~cm}^{-1}, \varepsilon_{300}=7.60 \mathrm{M}^{-1} \mathrm{~cm}^{-1}$, and $\left.\varepsilon_{320}=11.3 \mathrm{M}^{-1} \mathrm{~cm}^{-1}\right)$ and GA $\left(\varepsilon_{260}=2.60 \mathrm{M}^{-1} \mathrm{~cm}^{-1}, \varepsilon_{270}=\right.$ $2.50 \mathrm{M}^{-1} \mathrm{~cm}^{-1}, \varepsilon_{280}=2.20 \mathrm{M}^{-1} \mathrm{~cm}^{-1}, \varepsilon_{290}=1.70 \mathrm{M}^{-1} \mathrm{~cm}^{-1}$, $\varepsilon_{300}=1.40 \mathrm{M}^{-1} \mathrm{~cm}^{-1}$, and $\varepsilon_{320}=1.00 \mathrm{M}^{-1} \mathrm{~cm}^{-1}$ ) using the Beer's law equation:

$$
A=\varepsilon b[\mathrm{X}]
$$


for a path length $b=1.0 \mathrm{~cm}$ and the measured absorbance of individual standard solutions (X = GA or PA) of $[\mathrm{GA}]=90.3$ $\mathrm{mM}$ and $[\mathrm{PA}]=28.8 \mathrm{mM}$. Microsoft Excel Solver was used to solve the actual initial concentrations for GA and PA in the experimental mixture, which were typically ca. $[\mathrm{PA}]_{0}=27.9$ $\mathrm{mM}$ and $[\mathrm{GA}]_{0}=235.6 \mathrm{mM}^{28}$ More details about this calculation can be found in the Supporting Information.

Samples for ion chromatography were diluted 500 times with ultrapure water before injection with an autosampler (Dionex AS) in an IC (Dionex ICS-2000) provided with an IonPack AS11-HC (2 mm) analytical column and a conductivity detector. An ESI probe interfaced the output of the conductivity detector to a mass spectrometer (Thermo Scientific, MSQ Plus). The same chromatograph and mass spectrometer conditions previously established by Zhou and Guzman $^{30}$ were used in this work. Briefly, the initial $1 \mathrm{mM}$ potassium hydroxide concentration at a flow of $0.38 \mathrm{~mL} \mathrm{~min}^{-1}$ was increased following three linear gradient steps $(1.4 \mathrm{mM}$ $\mathrm{min}^{-1}$ up to $15 \mathrm{mM}, 1.5 \mathrm{mM} \mathrm{min}{ }^{-1}$ up to $30 \mathrm{mM}$, and $3.0 \mathrm{mM}$ $\mathrm{min}^{-1}$ up to $\left.60 \mathrm{mM}\right) .^{30}$ For direct infusion analysis, samples were diluted 1000 times with ultrapure water and injected in the ESI-MS, which was operated in negative ion mode at $70 \mathrm{psi}$ nitrogen nebulizing gas, $450{ }^{\circ} \mathrm{C}, 2.4 \mathrm{kV}$ needle voltage, and 40 $\mathrm{V}$ cone voltage, unless otherwise indicated in the text.

NMR (Varian INOVA 400) spectra at room temperature were recorded using a $5 \mathrm{~mm}$ NMR tube (Wilmad) with 540 $\mu \mathrm{L}$ of sample spiked with $60 \mu \mathrm{L}$ of $\mathrm{D}_{2} \mathrm{O}$ (Cambridge Isotope, 99.9\%), for field-frequency lock doped with 3-(trimethylsilyl)1-propanesulfonic acid sodium salt (DSS, Sigma-Aldrich, 97\%) internal standard. A water suppression enhanced through $\mathrm{T}_{1}$ effects (WET) solvent suppression method was applied using VnmrJ 3.2 software to eliminate more than $99.3 \%$ of the $\mathrm{H}_{2} \mathrm{O}$ signal. Further details of the NMR methods can be found in the Supporting Information.

\section{RESULTS AND DISCUSSION}

Optical Properties. Figure 1 shows how UV-visible spectra for a mixture with $235.6 \mathrm{mM} \mathrm{GA}$ and $27.9 \mathrm{mM}$ PA in the presence of electrolytes under $1 \mathrm{~atm}$ air (experiment in Table 1) vary during the four stages described in Scheme 1. Before irradiation a peak at $\lambda=321 \mathrm{~nm}$ from PA is observed together with a shoulder at $\lambda=276 \mathrm{~nm}$ due to GA. After $6 \mathrm{~h}$ of irradiation, the loss of $\mathrm{C}=\mathrm{O}$ groups in the UV spectrum is registered due to photobleaching during stage I (Scheme 1). For the following $24 \mathrm{~h}$ of thermal aging in stage II, an absorbance increase is observed reflecting thermochromism. ${ }^{8}$ For the second irradiation period, which simulates a second daytime cycle (stage III in Scheme 1), photobleaching produces a practically identical spectrum to the one observed at the end of stage I. Similarly, a second nighttime cycle developing thermochromism in dark stage IV results in strong absorption that recovers to the level developed during stage II.

The optical properties of the mixture of products change during the four processing stages reflecting the presence of alcohol, aldehyde, and ether groups. ${ }^{8}$ During nighttime under mild atmospheric conditions, these functional groups react with low activation energy barriers to produce chromophoric species. For example, the self-condensation of aldehydes, ${ }^{31,32}$ the formation of alkenes from alcohols, ${ }^{33}$ and the esterification of acids, ${ }^{34}$ are viable atmospheric reactions. Particularly, unsaturated hydrocarbons can undergo facilitated hydration in the presence of light, ${ }^{35}$ which explains the photobleaching registered in the UV-visible spectra.



Figure 1. UV-visible absorption spectra (pink solid line) before photolysis, (red short dashed line) post-photolysis at the end of stage $\mathrm{I}$; (black dashed line) followed by $15 \mathrm{~h}$ of thermal aging at $298 \mathrm{~K}$ and $9 \mathrm{~h}$ at $323 \mathrm{~K}$ in stage II, (blue dash-dot-dot line) after a second $6 \mathrm{~h}$ photolysis in stage III, and (green dash-dot line) after a second thermal aging in stage IV. Experimental conditions: Mixture of [GA] $=235.6 \mathrm{mM}$ and $[\mathrm{PA}]=27.9 \mathrm{mM},\left[\mathrm{Na}^{+}\right]=545 \mathrm{mM},\left[\mathrm{SO}_{4}{ }^{2-}\right]=28.2$ $\mathrm{mM}$, and $\left[\mathrm{Cl}^{-}\right]=468 \mathrm{mM}$, at $\mathrm{pH} 1.0$ under 1 atm air.

Figure 2 shows the normalized areas integrated under the $\mathrm{UV}$-visible absorption spectra in the range $295 \leq \lambda \leq 500 \mathrm{~nm}$

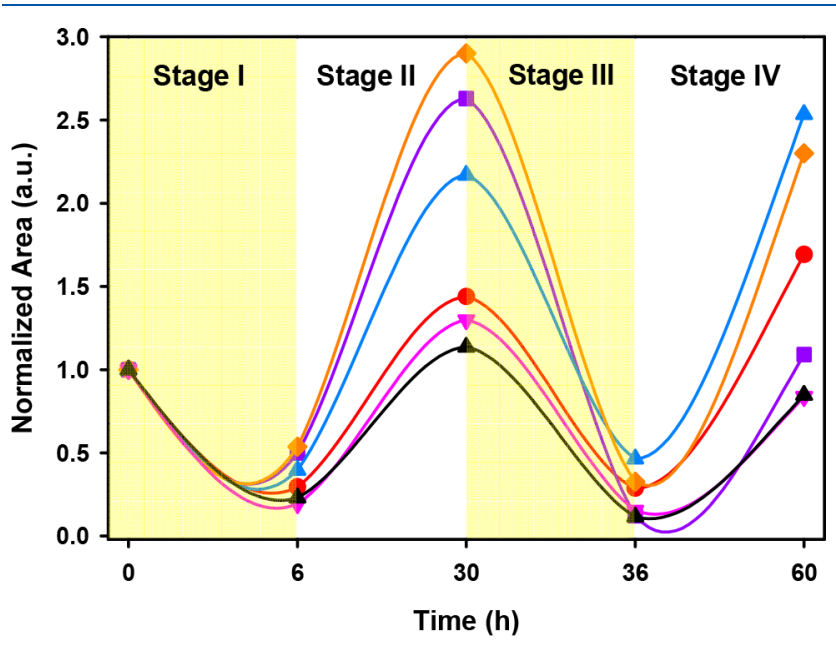

Figure 2. Normalized area $\left(\lambda_{\min }=295 \mathrm{~nm}\right.$ and $\left.\lambda_{\max }=500 \mathrm{~nm}\right)$ under the UV-visible absorption spectra for (red $\bullet$ ) an experiment, (blue A) control A in $\mathrm{N}_{2}$ (pink $\left.\boldsymbol{\nabla}\right)$, control B in $\mathrm{O}_{2}$, (violet $\boldsymbol{\square}$ ) control C without electrolytes, (orange control D without electrolytes in $\mathrm{N}_{2}$, and (black $\boldsymbol{\Delta}$ ) control $\mathrm{E}$ without electrolytes in $\mathrm{O}_{2}$. Experimental conditions are defined in Figure 1, and controls are given in Table 1.

for each stage in Scheme 1 for an experiment and all controls in Table 1. For normalization, all integrated areas were divided by its initial area before irradiation. Control $\mathrm{F}$ in the dark is not included in Figure 2 because it continued unchanged for the four stages. The largest change in Figure 2 corresponds to the comparison of stages I and III under irradiation displaying photobleaching versus dark (aging) stages II and IV corresponding to thermochromism. ${ }^{7,8}$ The presence of $\left[\mathrm{O}_{2}(\mathrm{aq})\right]$ and electrolytes affects each stage differently.

Some minor changes are observed at the end of stage I (Figure 2), and thermochromism becomes pronounced during stage II. After stage II, for increasing $\left[\mathrm{O}_{2}(\mathrm{aq})\right]$ in the presence 
of electrolytes (control A < experiment < control B in Table 1) thermochromism decreases. The areas at the end of stage II increase in the order $\mathrm{O}_{2}(\mathrm{~g})<$ air $<\mathrm{N}_{2}(\mathrm{~g}): 1.30<1.44<2.17$, which is $3.5( \pm 0.1)$ larger than observed for the self-reaction of GA in the presence of electrolytes. ${ }^{7}$ The same interpretation is applicable to the subset of experiments in the absence of electrolytes (controls C, D, and E). Electrolytes affect the development of thermochromism for stage II as demonstrated by contrasting the subsets in air (experiment vs control $\mathrm{C}$ ), in $\mathrm{N}_{2}(\mathrm{~g})$ (controls A vs D), and in $\mathrm{O}_{2}(\mathrm{~g})$ (controls B vs E). The sample with no electrolytes displays greater thermochromism in air, which comparatively increases in $\mathrm{N}_{2}(\mathrm{~g})$ but drops in $\mathrm{O}_{2}(\mathrm{~g})$. In stage III a second photobleaching cycle starts, while during stage IV, a reversal in the magnitude of the areas is observed for the pairs (1) experiments and control C, (2) controls A and D, and (3) controls B and E. However, the previous absorption enhancement due to the presence of electrolytes is much less pronounced for the latter case in 1 atm $\mathrm{O}_{2}(\mathrm{~g})$.

In summary, the presence of $\mathrm{O}_{2}$ is detrimental for the formation of chromophores. Electrolytes play a significant different role enhancing thermochromism in stage IV and diminishing it in stage II. The previous observation implies that the formation of complex polyfunctional $\mathrm{C}_{x} \mathrm{H}_{y} \mathrm{O}_{z}$ molecules observed at the end of stages I and II contribute to the production of less oxygenated species as shown by the relatively lower number of peaks in the $65-85 \mathrm{ppm}$ region of the ${ }^{13} \mathrm{C}$ NMR Spectra in Figure S1 (Supporting Information) compared to stages III and IV.

These new $\mathrm{C}_{x} \mathrm{H}_{y} \mathrm{O}_{z}$ species created from the mix of $\sim 28 \mathrm{mM}$ PA and $\sim 236 \mathrm{mM}$ GA undergo thermochromism through interactions with electrolytes after stage III. For comparison, the analysis of two cycles of photobleaching and thermochromism for the processing of $26.0 \mathrm{mM}$ PA (no GA) for controls G$M$ listed in Table S1 is available in Figure S2 (Supporting Information). The effect of electrolytes $\left(\left[\mathrm{Na}^{+}\right]=545 \mathrm{mM}\right.$, $\left[\mathrm{Cl}^{-}\right]=468 \mathrm{mM}$, and $\left[\mathrm{SO}_{4}{ }^{2-}\right]=28.2 \mathrm{mM}$, excluding $\left.\mathrm{NH}_{4}^{+}\right)$in Figure S2 agrees well with previous observations (for higher 80 $\mathrm{mM}$ solutions of PA in $2 \mathrm{M}$ ammonium bisulfate $)^{8}$ for the enhancement of thermochromism for PA alone during stages II and IV. Thus, thermochromism increases (Figures 2) with higher ionic strength (from inert electrolytes) and temperature, which promotes the dehydration of hydroxyl functional groups in alcohols $>\mathrm{CH}-\mathrm{C}(\mathrm{OH})<$ to form olefin groups $>\mathrm{C}=\mathrm{C}<.^{8}$

The hydration of unsaturated carbons is facilitated through photoinduced reactions in water. ${ }^{8}$ GA behaves as a typical species that can alter the reactivity of PA by cross-reacting with it, which affects the composition of the complex organic matter created. As a result, the new organic matter from the crossreaction possesses a higher $\mathrm{O} / \mathrm{C}$ ratio of $0.83-1.20$ compared to $0.71-1.00$ for the photoproducts of PA in the absence of GA. To sum up, the optical properties of the mixture along the different stages in Scheme 1 are affected by multiple functional groups in the photolyzed and thermally aged samples. The complex chemical composition of the products should enable light interactions (absorption and scattering) in the presence of electrolytes. ${ }^{8,9}$ The presence of electrolytes and dissolved $\mathrm{O}_{2}$ do affect the chemical reactivity of the organic species upon irradiation and thermal aging.

Identification of Products. The cross reaction products for the photolysis of GA and PA mixtures are analyzed by (1) IC-ESI-MS and (2) direct infusion ESI-MS, excellent techniques for species possessing $-\mathrm{COOH}$ groups. The information from direct infusion ESI-MS reveals the mass-tocharge ratio $(m / z)$ for all anionic products present in the sample. IC-ESI-MS also provides $\mathrm{m} / z$ values, but after chromatographic separation of the mixture, which eliminates possible artifacts caused by infusing a mixture of products directly. The data below for both methods reports a similar composition of product for the experiment and control C, suggesting that the presence of inorganic electrolytes does not determine the structure of products.

Figure 3 shows chromatograms with conductivity and ESIMS detection in the negative ion mode for the same



Figure 3. Ion chromatogram with conductivity and ESI-MS (-) detection for the experiment in Figure 1 (A) before and (B) after $6 \mathrm{~h}$ of irradiation. Key for peaks: (1) PA $(m / z$ 87), (2) GA $(m / z 73),(3)$ chloride, (4) sulfate $\left(m / z\right.$ 97) $(5) \mathrm{C}_{6} \mathrm{H}_{9} \mathrm{O}_{5}{ }^{-}\left(\mathrm{m} / z\right.$ 161), (6) $\mathrm{C}_{5} \mathrm{H}_{7} \mathrm{O}_{5}{ }^{-}$ $(m / z 147)$, a shoulder of $\mathrm{C}_{6} \mathrm{H}_{9} \mathrm{O}_{5}^{-}(\mathrm{m} / z 161)$, and 2-(3-oxobutan-2yloxy)-2-hydroxypropionic acid $\left(\mathrm{C}_{7} \mathrm{H}_{11} \mathrm{O}_{5}{ }^{-}, m / z\right.$ 175), (7) a diastereomer of 2,3-dimethyltartaric acid $\left(\mathrm{C}_{6} \mathrm{H}_{9} \mathrm{O}_{6}{ }^{-}, \mathrm{m} / z\right.$ 177), (8) a second diastereomer of 2,3-dimethyltartaric acid and $\mathrm{C}_{5} \mathrm{H}_{7} \mathrm{O}_{6}^{-}(\mathrm{m} / z$ 163), (9) tartaric acid $(\mathrm{m} / \mathrm{z} 149)$, and (10) oxalic acid $(\mathrm{m} / \mathrm{z} 89)$.

experiment in Figure 1 before and after $6 \mathrm{~h}$ photolysis. In Figure $3 \mathrm{~A}$ before irradiation, peaks 1 through 4 eluting at $6.624,10.674,11.900$, and $19.487 \mathrm{~min}$ in the conductivity detector are assigned by their $\mathrm{m} / z$ values and with matching standards to pyruvate $\left(\mathrm{C}_{3} \mathrm{H}_{3} \mathrm{O}_{3}{ }^{-}, \mathrm{m} / z\right.$ 87), glyoxylate $\left(\mathrm{C}_{2} \mathrm{H}_{1} \mathrm{O}_{3}{ }^{-}, \mathrm{m} / z\right.$ 73), chloride $\left(\mathrm{Cl}^{-}\right)$, and bisulfate $\left(\mathrm{HSO}_{4}{ }^{-}\right.$, $\mathrm{m} / z$ 97), respectively.

Upon $6 \mathrm{~h}$ of photolysis, new peaks 6, 7, and 8 elute in Figure $3 \mathrm{~B}$ and correspond to the products from the self-photoreaction of $\mathrm{PA},{ }^{3,27}$ 2-(3-oxobutan-2-yloxy)-2-hydroxypropionate $\left(\mathrm{C}_{7} \mathrm{H}_{11} \mathrm{O}_{5}{ }^{-}, m / z 175\right)$, and two diastereomers of 2,3dimethyltartrate $\left(\mathrm{C}_{6} \mathrm{H}_{9} \mathrm{O}_{6}{ }^{-}, \mathrm{m} / z\right.$ 177) ${ }^{6,26,27}$ Peaks 9 and 10 are assigned to a trace of tartrate $\left(\mathrm{C}_{7} \mathrm{H}_{11} \mathrm{O}_{5}{ }^{-}, \mathrm{m} / z 149\right.$, a selfreaction product of $\mathrm{GA}$ ) eluting at $19.086 \mathrm{~min}$, and to a trace 
of oxalate $\left(\mathrm{C}_{2} \mathrm{H}_{1} \mathrm{O}_{4}^{-}, \mathrm{m} / z 89\right.$, at $\left.20.937 \mathrm{~min}\right)$, as observed in the photolysis of GA alone. ${ }^{7}$ Three additional new peaks labeled 5, 6, and 8 appear in the conductivity detector due exclusively to the cross-reaction of GA with PA. However, some conductivity peaks correspond to overlapping species based on the distinctive $m / z$ values extracted with the help of the MS detector. For example, peak 6 contains anions at $\mathrm{m} / z$ 147,161 , and 175 , while peak 8 includes the anions at $m / z 177$ and 163, which can be resolved as extracted ions. However, because the species at $m / z 163$ is absent in experiments with pure PA or GA, ${ }^{6,7,26,27}$ this species must be a cross photolysis product of GA and PA. The extracted ion count at $\mathrm{m} / z 175$ and 177 shows that there are one and two peaks in the chromatogram (Figure 3B) for each of them, respectively.

The peak eluting at $5.796 \mathrm{~min}$ for $m / z 175$ in Figure 3B is assigned to 2-(3-oxobutan-2-yloxy)-2-hydroxypropionate or simply an oxo- $\mathrm{C}_{7}$ product of $\mathrm{PA},{ }^{3}$ whose area grows at longer irradiation times. The other major photoproducts with a formula mass of $178 \mathrm{Da}$ originate from the self-reaction of PA, and elute closely at 17.927 and $18.538 \mathrm{~min}$ in the conductivity detector (peaks 7 and 8 in Figure 3B). Based on previous work for the self-photoreaction of $\mathrm{PA}^{6}{ }^{6}$ the peaks at 17.927 and $18.538 \mathrm{~min}$ are assigned to two diastereomers $(2 \mathrm{R}, 3 \mathrm{R}$ and 2R,3S) of 2,3-dimethyltartaric acid (Figure S4, Supporting Information) produced from the combination of ketyl radicals of PA, $\mathrm{K}^{\bullet}$. In conclusion, the new species for peaks 5,6 , and 8 with molecular mass of 162,148 , and $164 \mathrm{Da}$, respectively, result from the cross-photoreaction of GA and PA. The new $\mathrm{C}_{5} \mathrm{H}_{8} \mathrm{O}_{5}(148 \mathrm{Da})$ molecule eluting in peak 5 with $\mathrm{m} / z 147$ is proposed to be 2-hydroxy-2-(2-oxopropoxy)acetic acid (oxo$\mathrm{C}_{5}$ cross-product) or an isomer. Coeluting with the previous is a similar $\mathrm{C}_{6} \mathrm{H}_{10} \mathrm{O}_{5}(162 \mathrm{Da})$ molecule contributing to peak 6 with $\mathrm{m} / z \quad 161$ tentatively assigned to 2-hydroxy-2-((1oxopropan-2-yl)oxy)propanoic acid (oxo- $\mathrm{C}_{6}$ cross-product), which at its tail overlaps with 2-hydroxy-2-((3-oxobutan-2yl)oxy)propanoic acid $(176 \mathrm{Da})$ (oxo- $\mathrm{C}_{7}$ product of $\mathrm{PA}$ ). Finally, the new $\mathrm{C}_{5} \mathrm{H}_{8} \mathrm{O}_{6}(164 \mathrm{Da})$ molecule is proposed to be 2,3-dihydroxy-2-methylsuccinic acid or an isomer, and elutes with peak 8 overlapping 2,3-dimethyltartaric acid (178 Da). Therefore, the new species in peaks 5, 6, and 8 should have similar structures to the coeluting species listed above.

Figure 4 shows direct infusion ESI-MS spectra reflecting composition changes before and after $1,2,4$, and $6 \mathrm{~h}$ of irradiation for the experiment with GA and PA. No products heavier than $250 \mathrm{Da}$ are observed during irradiation. The cross-reaction products with general formulas $\mathrm{C}_{5} \mathrm{H}_{8} \mathrm{O}_{5}$ (148 $\mathrm{Da}), \mathrm{C}_{6} \mathrm{H}_{10} \mathrm{O}_{5}(162 \mathrm{Da})$, and $\mathrm{C}_{5} \mathrm{H}_{8} \mathrm{O}_{6}(164 \mathrm{Da})$ are observed after irradiation for $1 \mathrm{~h}$.

The peaks in Figure 4 with $m / z 127$ and 129, which would correspond to compounds with formula mass of 128 and 130 $\mathrm{Da}$, are actually ascribed to clusters of the most abundant $(99.67 \%)$ gem-diol form of GA $\left(K_{\text {hyd }}=\right.$ [gem-diol form of $\mathrm{GA}] /[$ keto-form of GA $]=3.0 \times 10^{2}$ at $\left.298 \mathrm{~K}\right)^{36}$ with chloride. The area under each MS peak indicates that the abundance ratio of the anions $B_{127}=0.74$ and $B_{129}=0.26$ is related by the natural abundance of ${ }^{35} \mathrm{Cl}$ to ${ }^{37} \mathrm{Cl}^{37}$ (Figure S3A, Supporting Information). A similar isotopic signature for one chlorine in the cluster, $B_{127} / B_{129}=0.74 / 0.26$, is observed for the photolysis of $252.1 \mathrm{mM}$ GA with electrolytes in air $^{7}$ (Figure $\mathrm{S} 3 \mathrm{~B}$, Supporting Information). Because neither of the peaks at $\mathrm{m} / z 127$ and 129 is detected in the IC-ESI-MS chromatograms, they are interpreted as ESI clusters and not actual products.

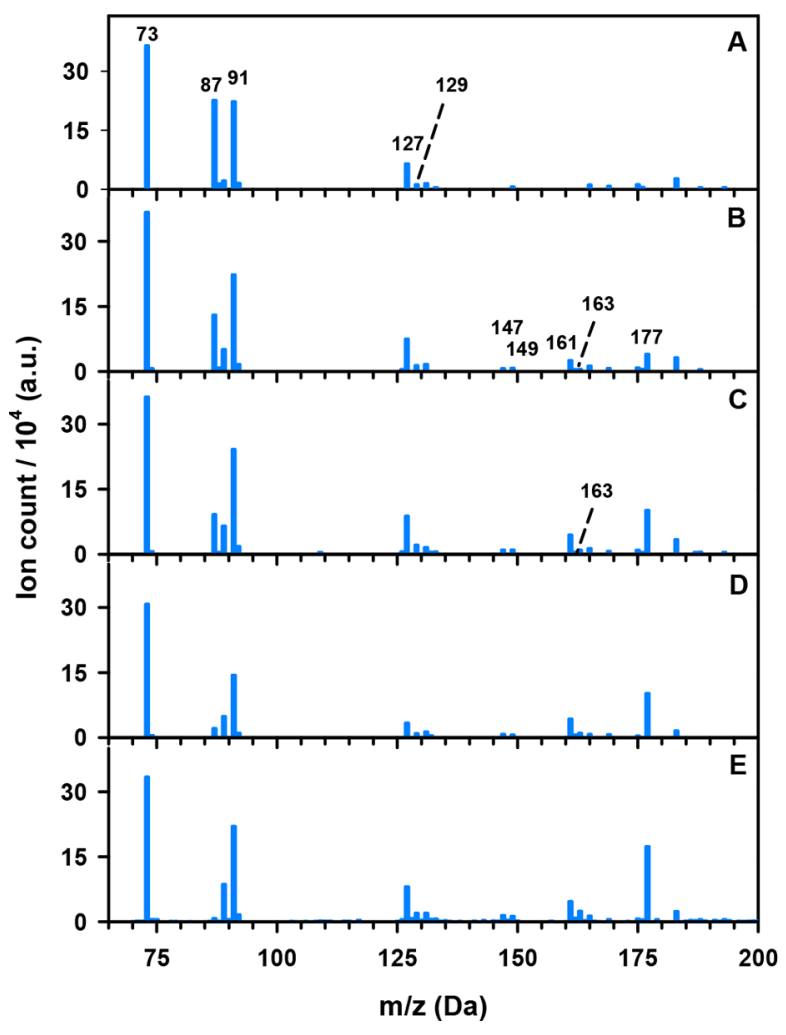

Figure 4. ESI-MS(-) spectra for the experiment in Figure 1 during stage I (Scheme 1) (A) before photolysis, and after (B) 1, (C) 2, (D) 4 , and (E) $6 \mathrm{~h}$ of irradiation.

The change in the ion count for direct infusion ESI-MS and IC-MS for GA, PA, and the photoproducts during the initial photolysis stage is shown in Figure $5 \mathrm{~A}$ and $5 \mathrm{~B}$, respectively. GA $(m / z 73)$ and PA $(m / z 87)$ decay in the time series of Figure $5 \mathrm{~A}$ due to photolysis in stage $\mathrm{I}$, both first order reactions in the concentration of each reactant. ${ }^{38}$ The species that grow with irradiation time are those identified above with a mass of 162, 164, and $178 \mathrm{Da}$. Figure 5B shows how the areas under chromatographically separated extracted ion peaks change for reactants and photoproducts. The mass spectrometer allows the identification of species that could coelute at the same retention time by distinguishing their different $\mathrm{m} / z$ values. The species eluting at $4.8 \mathrm{~min}(\mathrm{~m} / z 161), 5.9 \mathrm{~min}(\mathrm{~m} / \mathrm{z}$ 175 and 161$), 18.0 \mathrm{~min}(\mathrm{~m} / z 177)$, and $18.6 \mathrm{~min}(\mathrm{~m} / z 177$, $163)$ grow exponentially over time in Figure 5B. However, the area for the peak at $m / z 175$ reaches a steady level during the beginning stage of photolysis. A comparison to the results from PA photolyzed controls G to M (Table S1, Supporting Information) indicates that the efficiency for the production of 2-(3-oxobutan-2-yloxy)-2-hydroxypropionic acid $(\mathrm{m} / z \mathrm{175})$ is largely diminished by the presence of GA.

The use of NMR spectroscopy provides additional structural information to characterize the photolysis mixture. Figure 6 displays the ${ }^{13} \mathrm{C}$ NMR spectrum of a photolyzed mixture of GA and PA after $6 \mathrm{~h}$ irradiation (red trace) compared to the spectrum before photolysis (black trace). The signals at $\delta=$ $0.000,17.594,21.701$, and 56.964 ppm correspond to DSS. There are three peaks that belong to the carbonyl form of PA at the following chemical shifts: (1) $28.496 \mathrm{ppm}$ for the $-\mathrm{CH}_{3}$ carbon, (2) $166.377 \mathrm{ppm}$ for the $-\mathrm{COOH}$ carbon, and (3) $200.01 \mathrm{ppm}$ for the $\mathrm{C}=\mathrm{O}$ carbon in PA. Similarly, there are three other peaks for the gem-diol form of PA, 2,2- 

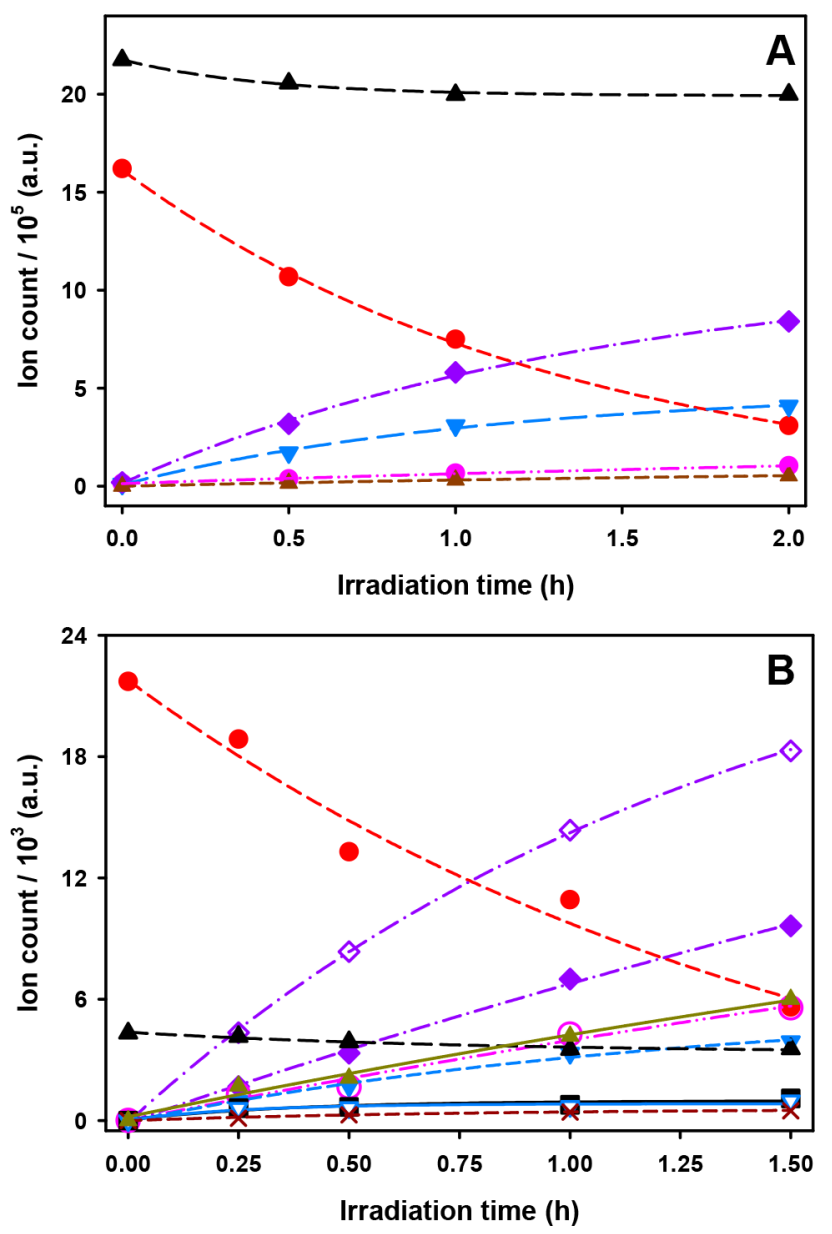

Figure 5. (A) Ion count from direct infusion ESI-MS(-) and (B) areas under the extracted IC-MS chromatographic peaks of species during the beginning of photolysis (stage I) for the experiment in Figure 1. Anions correspond to $\mathrm{m} / z$ (black $\boldsymbol{\Delta}$ ) 73, (red - ) 87, $($ brown $\times)$ 89, (dark yellow $\mathbf{\Delta}) 147$, (blue empty $\nabla$ and filled $\boldsymbol{\nabla}$ ) 161, (pink empty $\bigcirc$ and filled $\bullet$ ) 163, (filled $\square$ ) 175, and (violet and $\diamond) 177$.

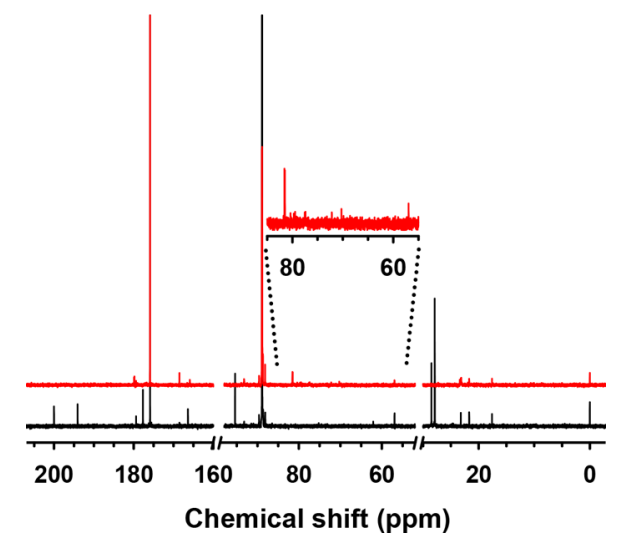

Figure 6. ${ }^{13} \mathrm{C}$ NMR spectra for the experiment in Figure 1 (bottom black line) before and (top red line) after $6 \mathrm{~h}$ photolysis. The inset shows the spectrum in the range 55-85 $\mathrm{ppm}$. No signals appear within the two excluded spectral brackets.

dihydroxypropanoic acid (DHPA), at (1) $27.891 \mathrm{ppm}$ for the $-\mathrm{CH}_{3}$ carbon, (2) $177.686 \mathrm{ppm}$ for the $-\mathrm{COOH}$ carbon, and (3) $95.412 \mathrm{ppm}$ for the carbon with two hydroxyl groups, $-\mathrm{C}(\mathrm{OH})_{2}$. For GA and its gem-diol, the $-\mathrm{COOH}$ groups are found at $\delta=194.090$ and $175.900 \mathrm{ppm}$, respectively. The gemdiol $\left(-\mathrm{C}(\mathrm{OH})_{2}\right)$ group of GA is found at $\delta 88.894 \mathrm{ppm}$ in Figure 6, while the aldehyde in equilibrium is at $\delta 175.886$. After $6 \mathrm{~h}$ of irradiation, the peaks for PA and DHPA at 27.891, 28.496, 95.412, 177.686, 194.090, and 200.001 ppm disappear. Simultaneously, the intensity drop of GA and PA, e.g., from their gem-diols in equilibrium respectively at $\delta=88.894$, $95.412 \mathrm{ppm}$ indicate their loss. The red trace for the products in Figure 6 reveals new signals in the region 155-185 ppm, which arise from carboxylic acids. In more detail, the peaks at $168.501 \mathrm{ppm}$ for oxalic acid and $179.401 \mathrm{ppm}$ for formic acid both from GA self-reaction, and $179.912 \mathrm{ppm}$ for the oxo- $\mathrm{C}_{7}$ product of PA self-reaction are accompanied by new crossproducts signals at 165.891 and $179.806 \mathrm{ppm}$. The appearance of ether groups is evidenced by new peaks within the $40-80$ ppm range ${ }^{39}(\delta=70.278,72.179,77.397,77.535,79.489$, $79.751 \mathrm{ppm})$ that grow during the post-irradiation period for the GA + PA mixture. Similar observations have been made for experiments with individual $\mathrm{GA}^{7}$ or $\mathrm{PA}^{6,26}$ Because GA is consumed over time during the cross photolysis reaction, as shown by the data in Figure 3, the large intensity peak for a carbonyl at $\delta=175.895 \mathrm{ppm}$ that practically overlaps the carbonyl form of GA reflects the formation of aldehyde products. This observation is also confirmed by the results in Figure 6 that display the production of aldehydes. In summary, these data provide additional evidence that the $\mathrm{C}_{5^{-}}$and $\mathrm{C}_{6}$ carboxylic acids of mass 148, 162, and 164 Da possess ether and aldehyde groups. Additional information, including $1 \mathrm{D}{ }^{1} \mathrm{H}$ and ${ }^{13} \mathrm{C}$ NMR, and $2 \mathrm{D}$ gCOSY and HSQC, is provided in the Supporting Information (Figures S5-S7).

Figure 7 shows the ion count change over the different processing stages in Scheme 1 for the experiment with GA and PA. Initial photoproducts can be consumed during the second photolysis (Stage III), because of their chromophoric carbonyl groups. The lack of major changes in the mass composition observed in Figure 7 after Stage I indicates that persistent species capable of undergoing reversible thermochromism and photobleaching are formed. Additionally, the analysis of ${ }^{13} \mathrm{C}$ NMR spectra in the range of $\delta=65-85 \mathrm{ppm}$, corresponding to saturated carbon $\left(\mathrm{sp}^{3}\right)$ arising from hydrocarbons with ether groups, ${ }^{39}$ shows new peaks appear during stage III and some disappear during stage IV (Figure S1, Supporting Information). This versatile behavior could be provided by some complex products capable of decomposing and recombining under sunlight irradiation, which have functional groups that can react in the dark with low activation energy.

Figure 8 is presented to explore whether higher mass products are generated during different stages of processing. Data in red columns (Figure 8) shows how the total ion count integrated in the interval 50-500 Da varies over all stages. Integrated ion count, IIC, is calculated from

$$
\mathrm{IIC}=\sum_{50}^{500} I_{i}
$$

where $I_{i}$ is the ion count for individual peaks of mass $i$. The blue columns in Figure 8 show the change in average mass, $\bar{M}$, calculated from

$$
\bar{M}=\frac{\sum_{50}^{500} m_{i} I_{i}}{\sum_{50}^{500} I_{i}}
$$




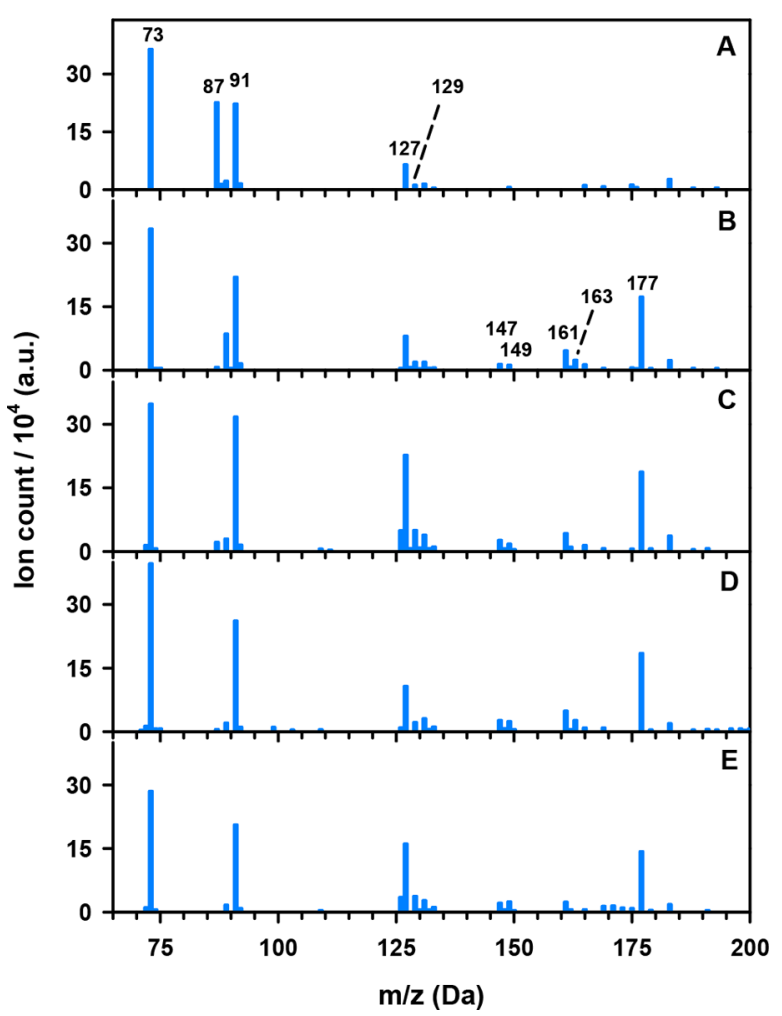

Figure 7. ESI-MS(-) spectra of the experiment in Figure 1 during stages I-IV in Scheme 1 (A) before photolysis, (B) after $6 \mathrm{~h}$ irradiation in stage $\mathrm{I},(\mathrm{C})$ at the end of the dark aging process in stage II, (D) after $6 \mathrm{~h}$ photolysis in stage III of panel C, and (E) after the completion of the aging process in stage IV.

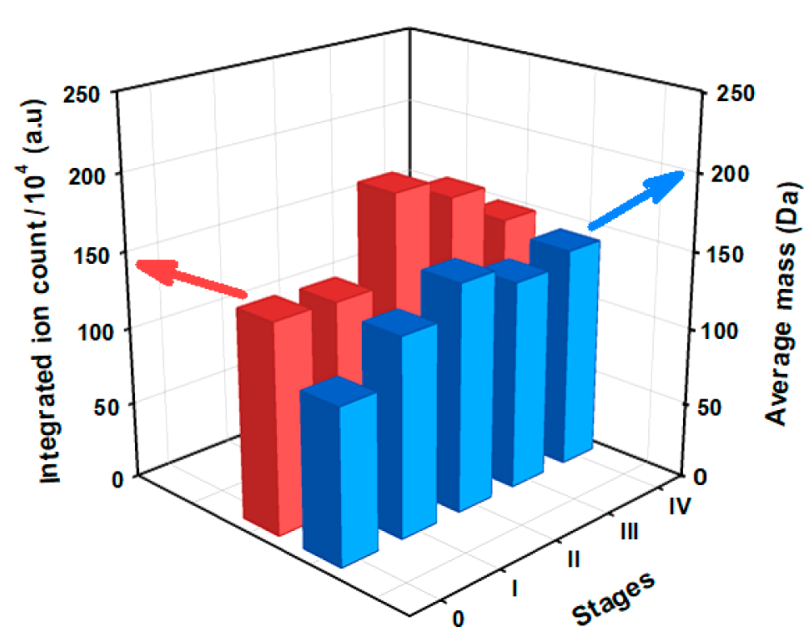

Figure 8. Integrated ion count and average mass in the ESI-MS for the experiment in Figure 1 before photolysis (0) and after the four stages in Scheme 1.

where $m_{i}$ stands for the mass of species $i$. It is clear that only for the transition from stage III to IV $\bar{M}$ decreases while IIC increases, which matches earlier observations for the decomposition of PA photoproducts during the aging process. ${ }^{9}$ No heavier mass than $250 \mathrm{Da}$ formed in the cross photoreaction of PA and GA. The change of $\bar{M}$ is small after the first photolysis and reflects that the loss of total organic carbon during the whole process is due mainly to decarboxylation of PA with a quantum yield $\Phi_{-\mathrm{CO}_{2}}^{\mathrm{PA}}=0.78$ in water, ${ }^{4}$ rather than to the much less efficient process for GA with $\Phi_{-\mathrm{CO}_{2}}^{\mathrm{GA}}=0.002$. $^{7}$

Mechanism of the Cross Photoreaction of GA and PA. From the learning disclosed in the discussion above and based on individual photolyses of $\mathrm{GA}^{7}$ and $\mathrm{PA},{ }^{6}$ a mechanism for the cross reaction of GA and PA via radical chemistry is proposed in Scheme 2. Comparing the stronger absorption of PA than GA in the actinic region and that in the hydration equilibria for the concentrations in Figure 1 there are 12 more carbonyl molecules of PA $\left(K_{\mathrm{Hyd}}=1.83\right)^{40}$ than GA $\left(K_{\mathrm{Hyd}}=300\right),{ }^{36}$ it is clear that the preferential absorption of PA initiates the reaction. Thus, first, PA is activated by light $(\lambda>300 \mathrm{~nm})$ to produce singlet excited state ${ }^{1} \mathrm{PA}^{*}$ (reaction R1a in Scheme 2), which undergoes intersystem crossing to a triplet ${ }^{3} \mathrm{PA}^{*}$ (reaction R1b) that has a lifetime of $\sim 0.5 \mu \mathrm{s}^{5}$ The thermal loss of ${ }^{3} \mathrm{PA}^{*}$ can occur by reaction $\mathrm{R} 2$.

Then, ${ }^{3} \mathrm{PA}^{*}$ can react via overall reaction $\mathrm{R} 3 \mathrm{a}+\mathrm{R} 3 \mathrm{~b}$ with the ground state of GA by proton-coupled electron transfer (PCET) to produce two possible triplet radical-ion pairs, ${ }^{3} \mathrm{RP}{ }_{1}$ and ${ }^{3} \mathrm{RP}_{2}$, which are analogous to those observed in frozen PA solutions. ${ }^{5}$ After protonation via reactions $\mathrm{R} 5 \mathrm{a}$ and $\mathrm{R} 5 \mathrm{~b}$ and deprotonation via reactions $\mathrm{R} 6 \mathrm{a}$ and $\mathrm{R} 6 \mathrm{~b}$, the radical anions and radical cations respectively form the pairs of ketyl (the lactic acid radical $\mathrm{K}^{\bullet}$ and the glycolic acid radical $\mathrm{Y}^{\bullet}$ ) and oxyl $\left(\mathrm{X}^{\bullet}\right.$ and $\mathrm{Z}^{\bullet}$ ) radicals. The same radicals should result from coordinated hydrogen atom transfer and electron transfer as an alternative to PCET. The major total organic carbon loss of the entire process is related to decarboxylation, which occurs in a few picoseconds and originates partially in reactions R7a and $\mathrm{R} 7 \mathrm{~b}$ from the oxyl radicals $\mathrm{Z}^{\bullet}$ and $\mathrm{X}^{\bullet}$ that form formyl and acetyl radicals $\mathrm{H}^{\bullet}$ and $\mathrm{Q}^{\bullet}$, respectively. All these new radicals can combine with neutral molecules available, such as $\mathrm{PA}$, DHPA, 2-hydroxyacrylic acid (the enol of PA), GA, and 2,2dihydroxyacetic acid. The previous reactions of radicals with neutral molecules (e.g., R8a and R8b) form secondary radicals, which combine with formyl (reaction R9) and acetyl (reactions $\mathrm{R} 10 \mathrm{a}$ and R10b) radicals. Subsequently, the formation of polyfunctional carboxylic acid termed oxo- $\mathrm{C}_{7}$ cross-intermediate, oxo- $\mathrm{C}_{8}$ intermediate of $\mathrm{PA}$, and oxo- $\mathrm{C}_{6}$ cross-intermediate proceeds. The resulting carboxylic acids can undergo decarboxylation contributing to the loss of total organic carbon by reactions $\mathrm{R} 11 \mathrm{a}, \mathrm{R} 11 \mathrm{~b}$, and $\mathrm{R} 11 \mathrm{c}$ to respectively produce an oxo- $\mathrm{C}_{6}$ cross-product, an oxo- $\mathrm{C}_{7}$ product of $\mathrm{PA}$, and an oxo- $\mathrm{C}_{5}$ cross-product. Decarboxylation rate constants for these kinds of reactions are in the order of $1 \times 10^{-3} \mathrm{~s}^{-1}$ at $298 \mathrm{~K}^{4}$ The formation of the oxo- $\mathrm{C}_{5}$ cross-product at $\mathrm{m} / z 147$ and the oxo- $\mathrm{C}_{6}$ cross-product at $m / z 161$ originate from the pathways described above, based on the evidence of detecting their precursor (intermediates) as anions at $\mathrm{m} / z 191$ and $\mathrm{m} / z$ 205 (Figure 3), respectively, before decarboxylation. The product 2,3-dihydroxy-2-methylsuccinic acid with the molecular mass of $164 \mathrm{Da}$ is formed from the combination of two ketyl radicals, $\mathrm{K}^{\bullet}$ and $\mathrm{Y}^{\bullet}$ in reaction $\mathrm{R} 12$, which should proceed with an approximate rate constant of $\sim 1.2 \times 10^{9} \mathrm{M}^{-1} \mathrm{~s}^{-1}$. In addition, reactions R13 and R14 in Scheme 2 show how the detected self-reaction products of PA (2,3-dimethyltartaric acid) and GA (tartaric acid) are formed, respectively.

This work also considers an alternative mechanism involving $\mathrm{H}$-abstraction from DHPA by preformed radicals (Scheme S1, Supporting Information). However, Scheme S1 is discarded based on the negative results for the detection of the hydrazones of 2-hydroxypropanal (MW 74.079) and acetoin 
Scheme 2. Proposed Mechanism for the Cross Reaction of Aqueous GA and PA

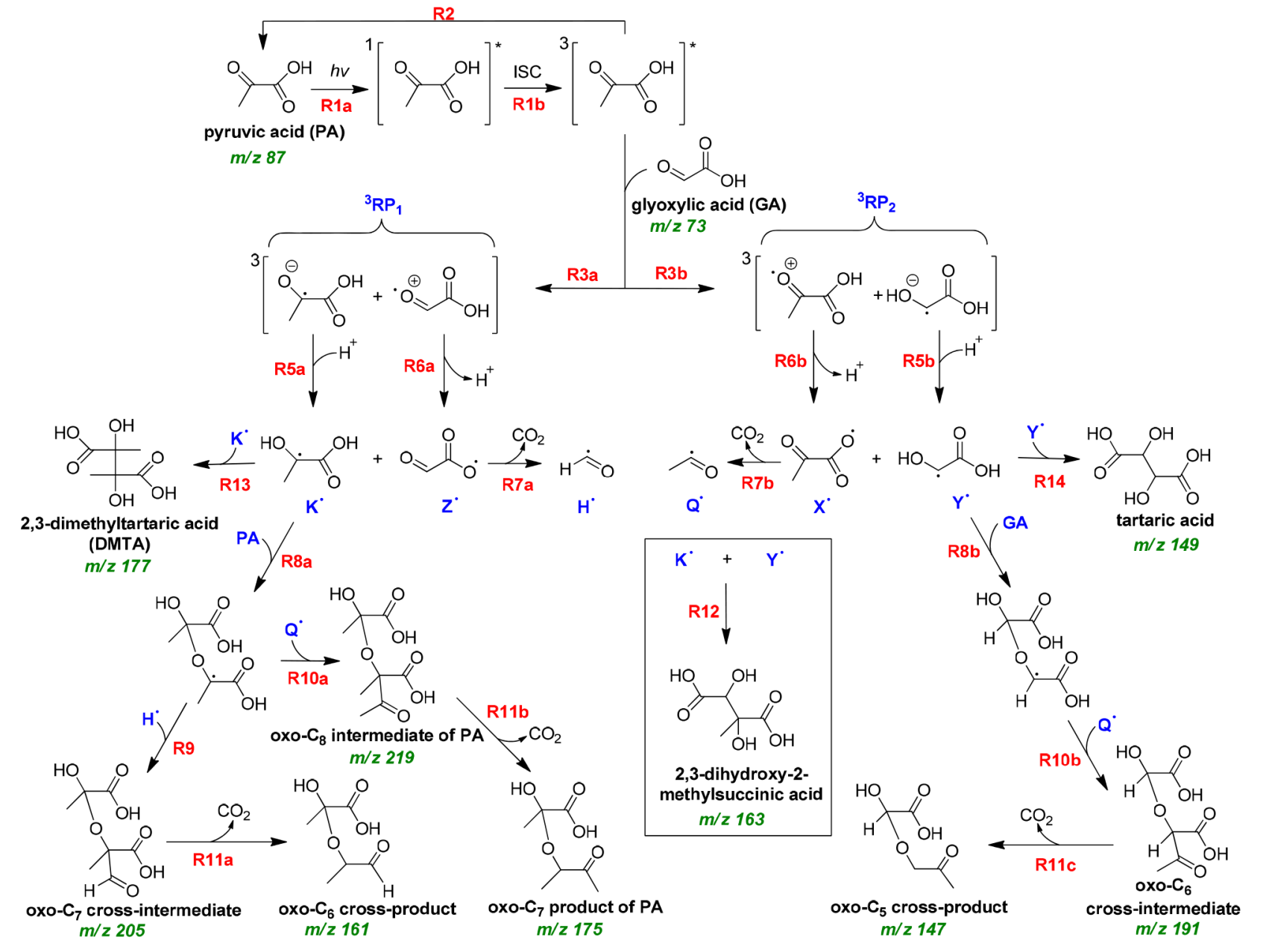

(MW 88.106) that should have developed peaks at $\mathrm{m} / z 253$ and 267 in the UHPLC-ESI-MS chromatogram of photolysis samples derivatized with DNPH. ${ }^{6}$ Instead, the UHPLC-MS analysis in the negative ionization mode shows the hydrazones with $m / z 341$ and 327 in Figure S8 (Supporting Information) have $\mathrm{C}=\mathrm{O}$ moieties, and also confirms the product of neutral mass 164 Da from reaction R12 (Scheme 2) does not have a carbonyl. Subtracting the DNPH fragment contributing 180 Da from the identified peaks with $\mathrm{m} / \mathrm{z} 341$ and 327 indicates these peaks correspond to the oxo- $\mathrm{C}_{6}$ cross-product and oxo$\mathrm{C}_{5}$ cross-product with neutral masses of 162 and $148 \mathrm{Da}$, respectively. Finally, other possibilities for the recombination of radicals and their addition to neutral molecules beyond Scheme 2 are considered in Scheme S2-S6 of the Supporting Information, where isomeric products such as peroxides are provided.

\section{CONCLUSIONS AND ATMOSPHERIC IMPLICATIONS}

This work has studied the cross photoreaction of GA and PA under simulated solar irradiation and the thermal processing of the photolyzed reaction mixture in the dark, also exploring the effects of inorganic electrolytes and $\left[\mathrm{O}_{2}(\mathrm{aq})\right]$. The lifetimes of aqueous GA and PA in the lower troposphere against direct photolysis at $40^{\circ}$ latitude are $11 \mathrm{~d}$ and $22 \mathrm{~min}$, respectively. ${ }^{6,7}$ The mechanism proposed via radicals of dicarbonyl species in water provides plausible pathways for the generation of complex organic matter. The cross reactivity of GA and PA produces species with higher $\mathrm{O} / \mathrm{C}$ ratios $(0.83-1.2)$ than observed for the self-reaction of PA $(0.71-1)$. Thus, GA increases the formation of more oxygenated species and expands the reactivity channels of PA in atmospheric aerosols. PA behaves as a photosensitizer that induces the reactivity of GA, forming new species. Therefore, similar processes should be operative in tropospheric waters to produce aqueous SOA of higher structural complexity than the precursors.

Structural information gained from direct infusion ESI-MS, IC-MS, and NMR spectroscopy, monitoring of optical property changes, and previous photolysis studies for GA and PA serves as the basis for the proposed mechanism (Scheme 2) for the cross photoreaction in water. ${ }^{3-7,26,27,40,41}$ The mechanism involves the direct participation of radicals and explains the production of the $\mathrm{C}_{5^{-}}$and $\mathrm{C}_{6}$-carboxylic acid cross-products with carbonyl and ether functional groups. In addition, other possibilities for the mechanism are depicted in Schemes S1-S6 (Supporting Information). The new species with molecular formulas $\mathrm{C}_{5} \mathrm{H}_{8} \mathrm{O}_{5}(148 \mathrm{Da}), \mathrm{C}_{6} \mathrm{H}_{10} \mathrm{O}_{5}$ (162 $\mathrm{Da})$, and $\mathrm{C}_{5} \mathrm{H}_{8} \mathrm{O}_{6}(164 \mathrm{Da})$ are enhanced in the presence of inorganic electrolytes, and are formed very favorably in air vs in $\mathrm{N}_{2}(\mathrm{~g})$. Notably, the cross reaction disfavors the production of the oxo- $\mathrm{C}_{7}$ product, which drops $\sim 34$ times compared to the self-reaction. However, the generation of 2,3-dimethyltartaric acid, another self-reaction product of PA, is still important 
during the cross reaction. The production of a trace of tartaric acid, a dimer of GA self-reaction, is detected.

Reproducible photobleaching and thermochromism periods coincide with irradiation and thermal aging stages. The environmental implications of this observation relate the optical properties of complex oligomers with the effect of inorganic electrolytes and dissolved $\mathrm{O}_{2}(\mathrm{aq})$ levels. Only an $\mathrm{O}_{2}(\mathrm{~g})$-saturated atmosphere has a detrimental effect on the development of thermochromism. However, the absorbance of products increases as the $\left[\mathrm{O}_{2}(\mathrm{aq})\right]$ decreases following the order $\mathrm{O}_{2}(\mathrm{~g})<$ air $<\mathrm{N}_{2}(\mathrm{~g})$. In this regard, the optical properties of organic aerosols are affected by their variable and complex particle size, structure, and chemical composition, which should be integrated with thermochromism and photobleaching parametrization factors into climate models. Accordingly, the variable direct and indirect effects of organic aerosols on the Earth's energy balance could be better constrained. $^{42,43}$

\section{ASSOCIATED CONTENT}

\section{S Supporting Information}

The Supporting Information is available free of charge on the ACS Publications website at DOI: 10.1021/acs.jpca.8b05724.

Additional experimental details, Table S1, Figures S1S8, and Schemes S1-S6 (PDF)

\section{AUTHOR INFORMATION}

\section{Corresponding Author}

*E-mail: marcelo.guzman@uky.edu. Phone: (859)323-2892.

\section{ORCID}

Marcelo I. Guzman: 0000-0002-6730-7766

\section{Notes}

The authors declare no competing financial interest.

\section{ACKNOWLEDGMENTS}

M.I.G. thanks the National Science Foundation for research funding under NSF CAREER award CHE-1255290. A.J.E. acknowledges support by the NASA Earth and Space Science Fellowship (NESSF) Program.

\section{ABBREVIATIONS}

DHPA, 2,2-dihydroxypropanoic acid; DSS, 3-(trimethylsilyl)1-propanesulfonic acid sodium salt; ESI, electrospray ionization; gCOSY, gradient correlation spectroscopy; HSQC, heteronuclear single quantum correlation; IC, ion chromatography; IIC, integrated ion count; GA, glyoxylic acid; average mass; $\bar{M}$, average mass; MS, mass spectrometry; PA, pyruvic acid; SOA, secondary organic aerosol; $\delta$, chemical shift; $\varepsilon_{\mathrm{GA}}$ molar absorption coefficient of glyoxylic acid; $\varepsilon_{\mathrm{GA}}$, molar absorption coefficient of pyruvic acid; 1D, one-dimensional; $2 \mathrm{D}$, two-dimensional

\section{REFERENCES}

(1) Ervens, B. Modeling the processing of aerosol and trace gases in clouds and fogs. Chem. Rev. 2015, 115, 4157-4198.

(2) McNeill, V. F. Aqueous organic chemistry in the atmosphere: Sources and chemical processing of organic aerosols. Environ. Sci. Technol. 2015, 49, 1237-1244.

(3) Guzman, M. I.; Colussi, A. J.; Hoffmann, M. R. Photoinduced oligomerization of aqueous pyruvic acid. J. Phys. Chem. A 2006, 110, $3619-3626$.
(4) Guzman, M. I.; Hoffmann, M. R.; Colussi, A. J. Photolysis of pyruvic acid in ice: Possible relevance to $\mathrm{CO}$ and $\mathrm{CO}_{2}$ ice core record anomalies. J. Geophys. Res.-Atmos. 2007, 112, D10123.

(5) Guzman, M. I.; Colussi, A.; Hoffmann, M. R. Photogeneration of distant radical pairs in aqueous pyruvic acid glasses. J. Phys. Chem. A 2006, 110, 931-935.

(6) Eugene, A. J.; Guzman, M. I. Reactivity of ketyl and acetyl radicals from direct solar actinic photolysis of aqueous pyruvic acid. $J$. Phys. Chem. A 2017, 121, 2924-2935.

(7) Eugene, A. J.; Xia, S.-S.; Guzman, M. I. Aqueous photochemistry of glyoxylic acid. J. Phys. Chem. A 2016, 120, 3817-3826.

(8) Rincon, A. G.; Guzman, M. I.; Hoffmann, M. R.; Colussi, A. J. Thermochromism of model organic aerosol matter. J. Phys. Chem. Lett. 2010, 1, 368-373.

(9) Rincon, A. G.; Guzman, M. I.; Hoffmann, M. R.; Colussi, A. J. Optical absorptivity versus molecular composition of model organic aerosol matter. J. Phys. Chem. A 2009, 113, 10512-10520.

(10) Das, S.; Bhattacharyya, J.; Mukhopadhyay, S. Mechanistic studies on the oxidation of glyoxylic and pyruvic acid by a $\left[\mathrm{Mn}_{4} \mathrm{O}_{6}\right]^{4+}$ core in aqueous media: Kinetics of oxo-bridge protonation. Helv. Chim. Acta 2006, 89, 1947-1958.

(11) Physical Constants of Organic Compounds. In CRC Handbook of Chemistry and Physics, 97th ed.;Haynes, W. M., Ed.; CRC Press/ Taylor \& Francis: Boca Raton, FL, 2017; Internet Version.

(12) Carlton, A. G.; Turpin, B. J.; Lim, H. J.; Altieri, K. E.; Seitzinger, S. Link between isoprene and secondary organic aerosol (SOA): Pyruvic acid oxidation yields low volatility organic acids in clouds. Geophys. Res. Lett. 2006, 33, L06822.

(13) Ervens, B.; Carlton, A. G.; Turpin, B. J.; Altieri, K. E.; Kreidenweis, S. M.; Feingold, G. Secondary organic aerosol yields from cloud-processing of isoprene oxidation products. Geophys. Res. Lett. 2008, 35, L02816.

(14) Nguyen, T. B.; Bateman, A. P.; Bones, D. L.; Nizkorodov, S. A.; Laskin, J.; Laskin, A. High-resolution mass spectrometry analysis of secondary organic aerosol generated by ozonolysis of isoprene. Atmos. Environ. 2010, 44, 1032-1042.

(15) Martín-Reviejo, M.; Wirtz, K. Is benzene a precursor for secondary organic aerosol? Environ. Sci. Technol. 2005, 39, 10451054.

(16) Bloss, C.; Wagner, V.; Jenkin, M. E.; Volkamer, R.; Bloss, W. J.; Lee, J. D.; Heard, D. E.; Wirtz, K.; Martin-Reviejo, M.; Rea, G.; et al. Development of a detailed chemical mechanism (MCMv3. 1) for the atmospheric oxidation of aromatic hydrocarbons. Atmos. Chem. Phys. 2005, 5, 641-664.

(17) Pillar, E. A.; Camm, R. C.; Guzman, M. I. Catechol oxidation by ozone and hydroxyl radicals at the air-water interface. Environ. Sci. Technol. 2014, 48, 14352-14360.

(18) Pillar, E. A.; Zhou, R.; Guzman, M. I. Heterogeneous oxidation of catechol. J. Phys. Chem. A 2015, 119, 10349-10359.

(19) Pillar, E. A.; Guzman, M. I. Oxidation of substituted catechols at the air-water interface: Production of carboxylic acids, quinones, and polyphenols. Environ. Sci. Technol. 2017, 51, 4951-4959.

(20) Kawamura, K.; Tachibana, E.; Okuzawa, K.; Aggarwal, S. G.; Kanaya, Y.; Wang, Z. F. High abundances of water-soluble dicarboxylic acids, ketocarboxylic acids and $\alpha$-dicarbonyls in the mountaintop aerosols over the North China Plain during wheat burning season. Atmos. Chem. Phys. 2013, 13, 8285-8302.

(21) Fu, P.; Kawamura, K.; Usukura, K.; Miura, K. Dicarboxylic acids, ketocarboxylic acids and glyoxal in the marine aerosols collected during a round-the-world cruise. Mar. Chem. 2013, 148, 22-32.

(22) Mkoma, S. L.; Kawamura, K. Molecular composition of dicarboxylic acids, ketocarboxylic acids, $\alpha$-dicarbonyls and fatty acids in atmospheric aerosols from Tanzania, East Africa during wet and dry seasons. Atmos. Chem. Phys. 2013, 13, 2235-2251.

(23) Lin, G.; Sillman, S.; Penner, J. E.; Ito, A. Global modeling of SOA: the use of different mechanisms for aqueous-phase formation. Atmos. Chem. Phys. 2014, 14, 5451-5475.

(24) Bao, L.; Matsumoto, M.; Kubota, T.; Sekiguchi, K.; Wang, Q.; Sakamoto, K. Gas/particle partitioning of low-molecular-weight 
dicarboxylic acids at a suburban site in Saitama, Japan. Atmos. Environ. 2012, 47, 546-553.

(25) Hatchard, C.; Parker, C. A. A new sensitive chemical actinometer. II. Potassium ferrioxalate as a standard chemical actinometer. Proc. R. Soc. London, Ser. A 1956, 235, 518-536.

(26) Eugene, A. J.; Guzman, M. I. Reply to "Comment on 'Reactivity of ketyl and acetyl radicals from direct solar actinic photolysis of aqueous pyruvic acid'. J. Phys. Chem. A 2017, 121, 8741-8744.

(27) Eugene, A. J.; Xia, S.-S.; Guzman, M. I. Negative production of acetoin in the photochemistry of aqueous pyruvic acid. Proc. Natl. Acad. Sci. U. S. A. 2013, 110, E4274-E4275.

(28) Harris, D. C. Quantitative chemical analysis, 7th ed.; W. H. Freeman: New York, 2007.

(29) Li, K.; Stefan, M. I.; Crittenden, J. C. UV photolysis of trichloroethylene: Product study and kinetic modeling. Environ. Sci. Technol. 2004, 38, 6685-6693.

(30) Zhou, R.; Guzman, M. I. $\mathrm{CO}_{2}$ reduction under periodic illumination of ZnS. J. Phys. Chem. C 2014, 118, 11649-11656.

(31) Shapiro, E. L.; Szprengiel, J.; Sareen, N.; Jen, C. N.; Giordano, M. R.; McNeill, V. F. Light-absorbing secondary organic material formed by glyoxal in aqueous aerosol mimics. Atmos. Chem. Phys. 2009, 9, 2289-2300.

(32) Noziere, B.; Dziedzic, P.; Córdova, A. Products and kinetics of the liquid-phase reaction of glyoxal catalyzed by ammonium ions $\left(\mathrm{NH}_{4}^{+}\right)$. J. Phys. Chem. A 2009, 113, 231-237.

(33) Jones, M.; Fleming, S. A. Organic Chemistry, 4th ed.; W. W. Norton \& Company Incorporated: New York, 2010.

(34) Minerath, E. C.; Casale, M. T.; Elrod, M. J. Kinetics feasibility study of alcohol sulfate esterification reactions in tropospheric aerosols. Environ. Sci. Technol. 2008, 42, 4410-4415.

(35) Kropp, P. J.; Reardon, E. J.; Gaibel, Z. L. F.; Williard, K. F.; Hattaway, J. H. Photochemistry of alkenes. Direct irradiation in hydroxylic media. J. Am. Chem. Soc. 1973, 95, 7058-7067.

(36) Sorensen, P. E.; Bruhn, K.; Lindelov, F.; et al. Kinetics and equilibria for the reversible hydration of the aldehyde group in glyoxylic acid. Acta Chem. Scand. 1974, 28a, 162-168.

(37) Shields, W. R.; Murphy, T. J.; Garner, E. L.; Dibeler, V. H. Absolute isotopic abundance ratio and the atomic weight of chlorine. J. Am. Chem. Soc. 1962, 84, 1519-1522.

(38) Engel, T.; Reid, P.; McQuarrie, D. A. Thermodynamics, statistical thermodynamics, and kinetics, 2nd ed.; Prentice Hall, 2009.

(39) Pavia, D.; Lampman, G.; Kriz, G. Introduction to spectroscopy, 3rd ed.; Brooks/Cole: USA, 2003.

(40) Guzman, M. I.; Hildebrandt, L.; Colussi, A. J.; Hoffmann, M. R. Cooperative hydration of pyruvic acid in ice. J. Am. Chem. Soc. 2006, $128,10621-10624$.

(41) Guzman, M. I.; Athalye, R. R.; Rodriguez, J. M. Concentration effects and ion properties controlling the fractionation of halides during aerosol formation. J. Phys. Chem. A 2012, 116, 5428-5435.

(42) Kanakidou, M.; Seinfeld, J. H.; Pandis, S. N.; Barnes, I.; Dentener, F. J.; Facchini, M. C.; Van Dingenen, R.; Ervens, B.; Nenes, A.; Nielsen, C. J.; et al. Organic aerosol and global climate modelling: a review. Atmos. Chem. Phys. 2005, 5, 1053-1123.

(43) Myhre, G.; Shindell, D.; Bréon, F.-M.; Collins, W.; Fuglestvedt, J.; Huang, J.; Koch, D.; Lamarque, J.-F.; Lee, D.; Mendoza, B. et al. Anthropogenic and natural radiative forcing. In Climate Change 2013: The Physical Science Basis. Contribution of Working Group I to the Fifth Assessment Report of the Intergovernmental Panel on Climate Change; Cambridge University Press: New York, 2013; pp 659-740. 